\title{
Experimental investigation of two-phase thermosyphon heat exchanger charged with acetone
}

\author{
Janusz T. Cieśliński ${ }^{1, *}$, and Maciej Fabrykiewicz ${ }^{1}$ \\ ${ }^{1}$ Gdańsk University of technology, Department of energy and Industrial Apparatus, 80-233 Gdańsk, Poland
}

\begin{abstract}
This paper presents thermal characteristics of prototype of a two-phase thermosyphon heat exchanger (TPTHEx) charged with acetone as a working fluid. The TPTHEx consists of two horizontal cylindrical vessels connected by two risers and a downcomer. Tube bundles placed in the lower and upper cylinders work as an evaporator and a condenser, respectively. The tested TPTHEx operates in a vacuum. Therefore, the working liquid is boiled in temperatures ranging from $33^{\circ} \mathrm{C}$ to $62^{\circ} \mathrm{C}$. The overall heat transfer coefficient (OHTC) of the tested TPTHEx was estimated by the use of the Wilson method and the modified Peclet equation. The results obtained indicate a superiority of water over acetone as a working fluid. Moreover, it was shown that having a lower pressure in the shell-side of TPTHEx results in a higher overall heat transfer coefficient. The Wilson method and the modified Peclet equation predict OHTC with satisfactory agreement.
\end{abstract}

\section{Introduction}

A two-phase thermosyphon heat exchanger (TPTHEx) is a special type of heat exchanger that is used in the food industry or chemical installations $[1,2]$. The mechanisms governing the heat transfer process in such heat exchangers with shell-side boiling and condensation are far from being completely understood [3]. Two-phase thermosyphons can be divided into two main groups: a thermosyphon tube with a countercurrent flow of liquid and vapor [4-6] and a two-phase loop where the evaporator is connected to the condenser by a riser and downcomer $[7,8]$. Different aspects of the performance of the two-phase thermosyphon have been investigated and the state-of-the-art design is presented in [9]. The purpose of the present study was to examine acetone as a working fluid as well as the influence of the operating pressure inside the shell on the overall performance of a two-phase thermosyphon heat exchanger. Distilled water as a reference working fluid was also used. A Wilson method was used to reduce the experimental data. Moreover, the modified Peclet equation was applied to estimate the overall heat transfer coefficient of the tested TPTHEx.

\section{Experimental setup}

The test stand consists of three main systems: the prototype TPTHEx, heating water loops and cooling water loops. The test facility is capable of determining the overall heat transfer coefficient of TPTHEx. A schematic diagram of the test stand is shown in Fig. 1.

Heating and cooling water loops each contain a centrifugal pump, a flowmeter and a vent tank. A district heating network and a cooling tower are used as a heat source and heat sink, respectively. Heating and cooling water flow rates are controlled by regulating valves and are measured by magnetic flowmeters Danfoss MAG 3100 which are accurate within $\pm 0.25 \%$ of the measured value. Pressure inside shell is measured by Trafag NA/8891 pressure transducer accurate to $\pm 0.3 \%$ of the measured value. The average temperature of the heating and cooling water at the inlet and outlet of the evaporator and condenser tube bundles of TPTHEx was measured using resistance temperature devices Pt100 with an accuracy of $\pm 0.1 \mathrm{~K}$.

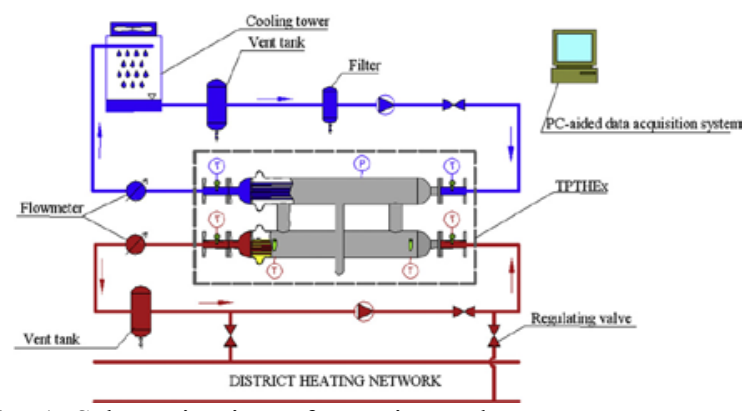

Fig. 1. Schematic view of experimental setup; T- temperature sensors and P-pressure sensors.

\subsection{Prototype two-phase thermosyphon heat exchanger}

The prototype two-phase thermosyphon is a shell and tube, horizontal heat exchanger in the form of a welded 1.4404 stainless steel construction. The shell consists of two cylindrical vessels, measuring $159 \mathrm{~mm}$ in diameter and $1 \mathrm{~m}$ in length, which are connected by two risers and

Corresponding author: jcieslin@pg.gda.pl 
a downcomer. The evaporator is designed as a tube bundle consisting of 19 smooth, tubes with a triangular arrangement and a pitch equal to $\mathrm{s} / \mathrm{d}=2.0$. The condenser is designed as a tube bundle consisting of 31 smooth stainless steel tubes (outside diameter was $10 \mathrm{~mm}$ ) with a triangular arrangement and pitch equal to $\mathrm{s} / \mathrm{d}=1.8$.

\subsection{Experimental procedure}

Before the tankage of the TPTHEx with working fluid, an absolute pressure of $5 \mathrm{kPa}$ was created inside the shell. During the tests the absolute pressure inside the shell ranged from 8 to $91 \mathrm{kPa}$, which corresponds to the operating temperatures from $33.7^{\circ} \mathrm{C}$ to $61.7^{\circ} \mathrm{C}$. The heating as well as cooling water mass flow rates ranged from 0.2 to $3.03 \mathrm{~kg} / \mathrm{s}$. The monitoring of the temperature and pressure readings was facilitated by the use of a PCaided data acquisition system. All data readings have been performed during steady-states. More details concerning the experimental setup and procedure are presented in [10].

\section{Data reduction}

\subsection{Evaporator heat flux}

Heat flux transferred in the evaporator was calculated using the formula

$$
\dot{q}_{e}=\frac{\dot{Q}_{e}}{A_{e}}
$$

where the heat transfer rate $\dot{Q}_{e}$ was estimated using the measured volume flow rate and the measured hot water temperatures at the inlet $t_{\mathrm{hot}, 1}$ and outlet $t_{\mathrm{hot}, 2}$ :

$$
\dot{Q}_{e}=\dot{V}_{h o t} \cdot \rho_{e, h o t} \cdot c_{p_{e, h o t}} \cdot\left(t_{h o t, 1}-t_{h o t, 2}\right)
$$

\subsection{Overall heat transfer coefficient according to the Wilson method}

The overall heat transfer coefficient according to the Wilson method was calculated as:

$$
k_{o, W}=\frac{1}{\frac{1}{k_{e, W}}+\frac{1}{k_{c, W}}}
$$

The overall heat transfer coefficient of evaporator $k_{e, W}$ was estimated as:

$$
k_{e, W}=\frac{1}{\frac{1}{\alpha_{e, i W}}+\frac{\delta_{t}}{\lambda_{t}}+\frac{1}{\alpha_{e, o W}}}
$$

The overall heat transfer coefficient of condenser $k_{c, W}$ was estimated as:

$$
k_{c, W}=\frac{1}{\frac{1}{\alpha_{c, i W}}+\frac{\delta_{t}}{\lambda_{t}}+\frac{1}{\alpha_{c, o W}}}
$$

Following the Wilson method, the heat transfer coefficient inside the tube can be estimated as :

- for $\dot{m}_{f, h o t}=$ const. and $\dot{m}_{f, \text { cold }}=$ var.

$$
\begin{gathered}
\alpha_{e, i, W}=\frac{1}{C_{3}-2 \cdot \frac{\delta_{W}}{\lambda_{W}}-\frac{1}{\alpha_{b o i}}-\frac{1}{\alpha_{c o n}}} \\
\alpha_{c, i, W}=\frac{1}{C_{2}-w_{c o l d}^{n}}
\end{gathered}
$$

- for $\dot{m}_{f, \text { cold }}=$ const. and $\dot{m}_{f, h o t}=$ var

$$
\begin{gathered}
\alpha_{c, i, W}=\frac{1}{C_{3}-2 \cdot \frac{\delta_{W}}{\lambda_{W}}-\frac{1}{\alpha_{b o i}}-\frac{1}{\alpha_{c o n}}} \\
\alpha_{e, i, W}=\frac{1}{C_{2}-w_{h o t}^{n}}
\end{gathered}
$$

$C_{2}$ and $C_{3}$ are Wilson method constants and were determined by the use of linear regression [11]. The pool boiling heat transfer coefficient $\alpha_{b o i}$ was predicted by the use of Cooper correlation [12]. The condensation heat transfer coefficient $\alpha_{c o n}$ was calculated from the Gutkowski correlation [13].

\subsection{Overall heat transfer coefficient according to the modified Peclet equation}

Following the approach proposed by Cieśliński and Fiuk in [10] the overall heat transfer coefficient for a twophase thermosyphon heat exchanger can be calculated as

$$
k_{o, P}=\frac{1}{\frac{A_{e} \cdot \Delta T_{e}}{\dot{Q}_{e}}+\frac{A_{c} \cdot \Delta T_{\mathcal{c}}}{\dot{Q}_{c}}}
$$

where the heat transfer rate transferred in evaporator $\dot{Q}_{e}$ is given by Eq. 2 and the heat transfer rate transferred in condenser $\dot{Q}_{c}$ is estimated using the formula:

$$
\dot{Q}_{c}=\dot{V}_{\text {cold }} \cdot \rho_{c, \text { cold }} \cdot c_{p_{c, \text { cold }}} \cdot\left(t_{\text {cold }, 1}-t_{\text {cold }, 2}\right)
$$

where the volume flow rate of cold water $\dot{V}_{\text {cold }}$, the temperature of the inlet $t_{c o l d, l}$ and the temperature of the outlet $t_{\text {cold }, 2}$ of the condenser were measured values. The mean evaporator fluid-to-wall temperature difference, $\Delta T_{e}$, reads

$$
\Delta T_{e}=\bar{t}_{h o t}-\bar{t}_{f}
$$

The mean condenser fluid-to-wall temperature difference, $\Delta T_{c}$, reads

$$
\Delta T_{c}=\bar{t}_{f}-\bar{t}_{\text {cold }}
$$


where $\bar{t}_{\text {hot }}$ and $\bar{t}_{\text {cold }}$ are the arithmetic means of the measured inlet and outlet temperatures of hot and cold water, respectively, and $\overline{t_{f}}$ is the arithmetic mean of measured working fluid temperature. The detail of the calculation procedure is given in [10].

\section{Results}

In order to validate the experimental apparatus and procedure, the present results obtained for distilled water as the working fluid were compared to the data reported by Cieśliński and Fiuk [10] for the same configuration of the TPTHEx (Fig. 2). The overall heat transfer coefficient was determined using a modified Peclet equation (Eq. 10). Keeping in mind the complexity of the heat transfer process occurring in TPTHEx, the agreement between the present results and the data published in [10] is satisfactory. These results confirm that the current facility can be used to provide highly repeatable data.

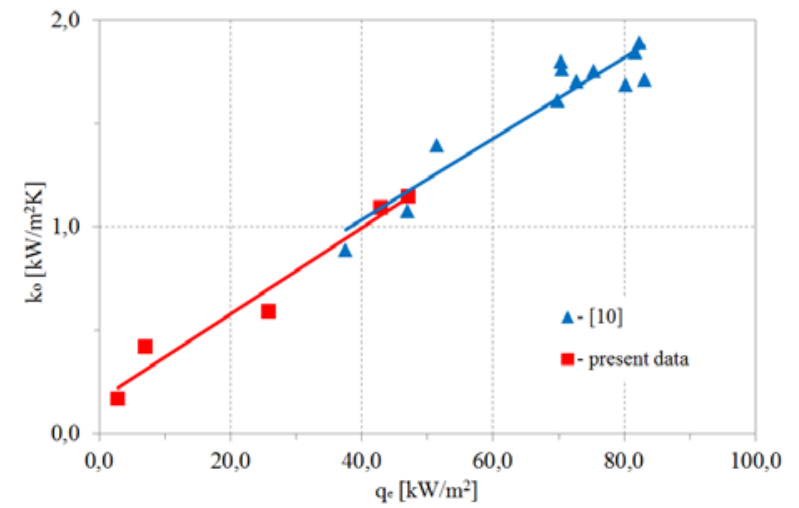

Fig. 2. Overall heat transfer coefficient vs. heat flux of evaporator for distilled water as the working fluid at an operating pressure inside the shell of about $13 \mathrm{kPa}$.

Figure 3 shows boiling curves of the TPTHEx evaporator for two tested working fluids, i.e. distilled water and acetone. The boiling curve for acetone is shifted right - towards higher wall superheat. It means that there was heat transfer deterioration. The obtained results confirm the tendency observed in the literature that water displays superiority over acetone during pool boiling heat transfer [14].

Figure 4 shows the influence of the operating pressure on TPTHEx evaporator performance with acetone as a working fluid. A decrease of the absolute pressure inside a shell from about 75 to $52 \mathrm{kPa}$ results in heat transfer deterioration - the boiling curve shifts left towards higher wall superheats. Again, the obtained results confirm the tendency observed in the literature, that a decrease in the operating pressure results in heat transfer deterioration during pool boiling $[15,16]$.

Figure 5 shows the overall heat transfer coefficient against the evaporator heat flux for water and acetone estimated by two methods, i.e. Wilson approach and modified Peclet equation. It is important that the Wilson method underestimated the OHTC for water - the difference is about $25 \%$ and overestimated the OHTC for acetone - the difference is about $33 \%$.

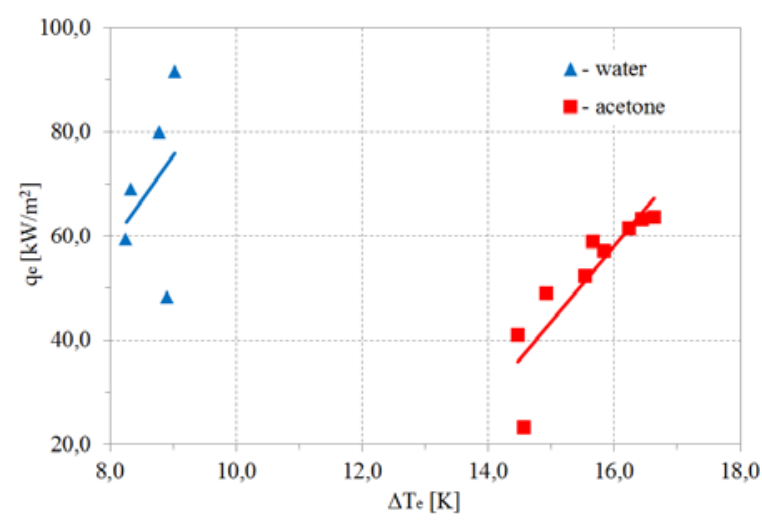

Fig. 3. Boiling curves of the TPTHEx evaporator for water and acetone.

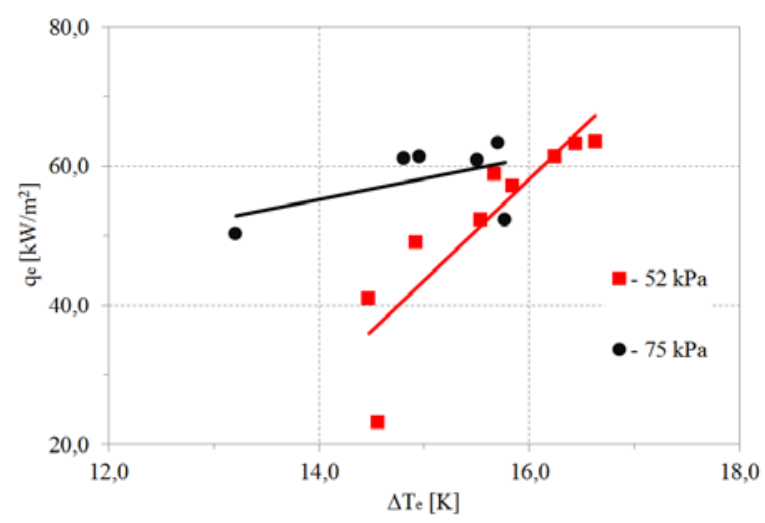

Fig. 4. Boiling curves of the TPTHEx evaporator for different operating pressure inside a shell.

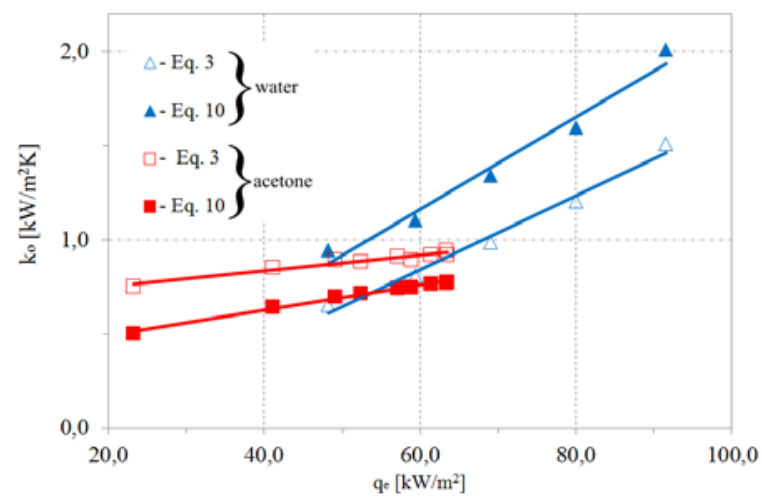

Fig. 5. Overall heat transfer coefficient vs. evaporator heat flux.

\section{Conclusions}

- It was shown that water displays superiority over acetone as a working fluid in the tested two-phase thermosyphon heat exchanger.

- The data obtained shows that an increase in the operating pressure results in performance improvement of the evaporator of the tested two-phase thermosyphon heat exchanger. 
- The Wilson method and the approach proposed by Cieśliński and Fiuk, which is based on the modified Peclet equation, predict the overall heat transfer coefficient of the tested two-phase thermosyphon heat exchanger with satisfactory agreement.

\section{References}

1. L.L. Vasiliev, Applied Thermal Engineering, 25, 119 (2005)

2. Ł. Vasiljew, Ł. Grakowicz, D.K. Chrustaljew, Teplowyje truby $w$ sistemach $s$ wozobnowliajemnymi istocznikami energii, Nauka $i$ Technika, Minsk (1988)

3. L.S. Pioro, I.L. Pioro, Industrial Two-Phase Thermosyphons, Begell House Inc., New York, Wallingford (UK) (1997)

4. S. Khandekar, M. Groll, Insights into the performance models of closed loop pulsating heat pipes and some design hints, Proc. 18th National \& 7th ISHMT-ASME Heat and Mass Transfer Conference, IIT Guwahati, India, Paper No: G-440 (2006)

5. M. Bezrodny, J. Goscik, Refrigeration AirConditioning Eng, 1, 5-10 (1997) (in Polish)

6. D. Chisholm, Heat Exchangers Design Handbook, Part 3, Thermal and Hydraulic Design of Heat Exchangers, Begell House Inc., New York, Wallingford (UK), Chapter 3.10.1 (1998)

7. N. Gavotti, F. Polášek, Proc. of Eurotherm Seminar No. 6, Single and Two-Phase Natural Circulation, Genoa, Italy, 229-238 (1999)

8. R. Khodabandeh, B. Palm, Proc. of the 5th ExHFT World Conference, Thessaloniki, Greece, 191-196 (2001)

9. J.T. Cieśliński, Archives of Thermodynamics, 37, 23-40 (2016)

10. J. T. Cieśliński, A. Fiuk, Appl. Therm. Eng, 51, 112118 (2013)

11. J.T. Cieśliński, J. Rubalewski, Technika Chłodnicza i Klimatyzacyjna, 195, 206-211 (2012) (in Polish)

12. M.G. Cooper, Adv. Heat Transfer, 16, 157-239 (1984)

13. K. Gutkowski, Refrigeration - Selected Numerical Problems, WNT Warsaw (1972) (in Polish)
14. S. Fazel, M. Jamialahmadi, A. Safekordi, Iran. J. Chem. Chem. Eng., 27, 135-150 (2008)

15. J.T. Cieśliński, K. Krasowski, J Enhanced Heat Transfer, 20, 165-177 (2013)

16. J.T. Cieśliński, T. Kaczmarczyk, Chemical and Process Engineering, 32, 321-332 (2011)

\section{Nomenclature}

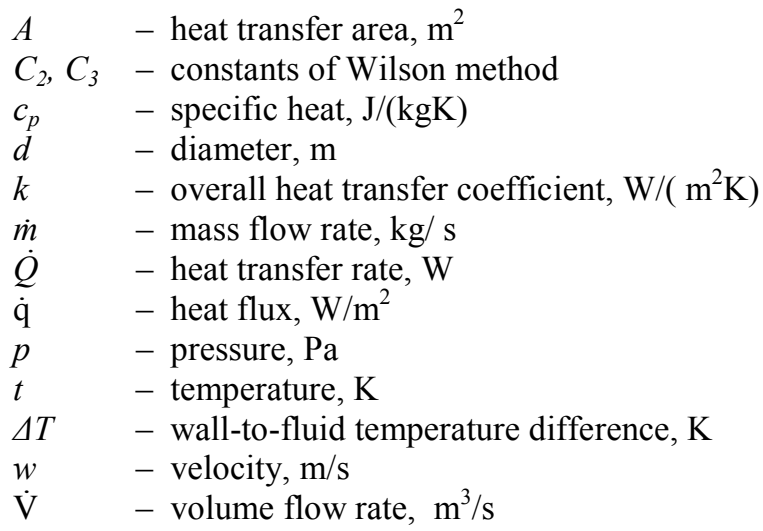

\section{Greek symbols}

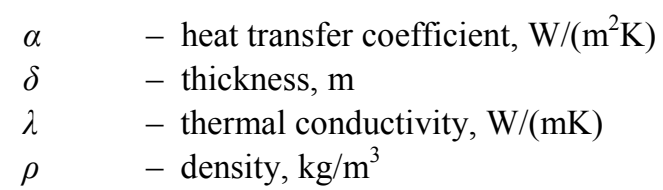

\section{Subscripts}

$\begin{array}{ll}\text { boi } & - \text { boiling } \\ c & - \text { condenser } \\ \text { cold } & - \text { cold water } \\ \text { con } & - \text { condensation } \\ e & - \text { evaporator } \\ f & - \text { working fluid } \\ h o t & - \text { hot water } \\ i & - \text { inside } \\ o & - \text { outside } \\ P & - \text { Peclet equation } \\ t & - \text { tube } \\ w & - \text { wall } \\ W & - \text { Wilson method } \\ 1 & - \text { inlet } \\ 2 & - \text { outlet }\end{array}$

